\section{P7 (continued)}

Background (Background, Rationale, Prior Research, and/or Theory): Optimizing students' school food environment with inclusion of locally grown foods and encouraging them to choose these options is a unique opportunity for schools to further promote student health and potentially decrease risk of obesity. Consumption of locally grown foods is associated with several health, environmental, economic and other benefits but is not clear what benefits resonate most with children.

Objective: The objective of this study was to determine what local food messages appeal to elementary school students to encourage their choice and consumption of locally grown vegetables at lunchtime at an urban low-income school district.

Study Design, Setting, Participants, Intervention: During afterschool programs, 3rd-5th grade students $(\mathrm{n}=100)$ completed an interactive local foods survey testing the appeal of six local food messages each touting a unique benefit, and knowledge of the meaning of "local food".

Outcome Measures and Analysis: Students' responses were collected and analyzed to determine the most appealing messages then stratified to determine differences in message appeal based on age, grade, and gender. Descriptive statistics, crosstabs and Chi-square tests were conducted.

Results: Local food messages related to strength/health (Superhero strong), and school/community (\#1 school) were most favored by students. Examining demographic differences, male students chose "Superhero strong" significantly more as their favorite message compared to female students $(53 \%$ versus $32 \%$ respectively) $(P<.05)$. The "\#1 school" message ranked as students' favorite message differently among 3rd (20\%), 4th (16\%), and 5th $(45 \%)$ graders $(P<.05)$. There were no differences in message appeal by age. Fifth grade students most frequently understood the concept of "local foods" (40\%) while only (2\%) of 3rd graders understood its meaning.

Conclusions and Implications: Overall, students found local food messages most appealing when they were based on providing strength and health or contributing to their sense of school pride. Using these messages to make local foods more appealing during school lunches could increase students' interest in them and encourage healthy eating.

Funding: University of Connecticut Collaboratory on School and Child Health.

\section{P8 Mississippi Retail Study: Assessing Food Availability in SNAP-Accepting Stores \\ Kaitlin DeWitt, MPH, MS, LDN, RDN, kd329@msstate.edu, Mississippi State University Extension Service, 1815 Popp's Ferry Road, Biloxi, MS 39532; Sylvia H. Byrd, PhD, LDN, RDN}

Background (Background, Rationale, Prior Research, and/or Theory): Supplemental Nutrition Assistance Program (SNAP) eligible adults and families with children in Mississippi face substantial rates of food insecurity. Compared to national data, Mississippians reported eating fewer fruits and vegetables and were more likely to be obese. Increasing healthy food availability in SNAPaccepting stores may improve Mississippians' health and eating behaviors.

Objective: The study objective was to examine the food environment of SNAP-accepting stores across Mississippi. Study Design, Setting, Participants, Intervention: This cross-sectional study was conducted from January to February 2017. All stores were identified from the United States Department of Agriculture SNAP-accepting store list $(n=3,585)$. Approximately the same proportion of stores from each county in Mississippi was surveyed to achieve a representative sample of stores $(n=465)$. Trained Mississippi State University Extension Service employees (Nutrition Educators and Extension Agents) and research team members collected data using a modified Nutrition Environment Measures Survey-Corner Store (NEMS-CS). Outcome Measures and Analysis: The outcome measure is the availability of food items, specifically milk, fruits, vegetables, grains, and protein sources, in SNAPaccepting stores in Mississippi. Food availability was measured by the percent of SNAP-accepting stores that were reported as carrying the food item.

Results: Of the 465 surveyed stores, 9\% $(n=42)$ did not supply milk. Canned fruits and vegetables were more available (93\% and $96 \%$ of stores, respectively) than fresh and frozen fruits and vegetables. Hot dog varieties were sold at more stores $(57 \%, \mathrm{n}=296)$ than ground beef varieties $(45 \%, \mathrm{n}=208)$. Bread was sold at $84.5 \%$ of the surveyed stores $(\mathrm{n}=393)$.

Conclusions and Implications: These findings provide an overview of food availability in SNAP-accepting retailers across Mississippi and will be used to inform future studies and pilot interventions to increase food availability for Mississippi's SNAP recipients.

Funding: Supplemental Nutrition Assistance Program-Education.

\section{Basic Food and Nutrition Knowledge}

\section{P9 A Nutrition Knowledge Comparison of Army Culinary Staff and the Soldiers They Feed}

Erik E.Serrano, Erik.E.Serrano.mil@mail.mil, U.S. Army Research Institute of Environmental Medicine, 10 General Greene Avenue, Natick, MA 01701;

Nicholas J. Armstrong, MS, RD;

Catherine M. Champagne, $P h D, R D$, Pennington

Biomedical Research Center; Adrienne Hatch, $M S, R D$,

U.S. Army Research Institute of Environmental

Medicine; Susan McGraw, BS; Renee E. Cole, PhD, RD, LD

Background (Background, Rationale, Prior Research, and/or Theory): Warfighter diet quality has a direct impact on health and performance. Military dining

Continued on page S12 


\section{P9 (continued)}

facilities (DFAC) are a common source of dietary intake and DFAC culinary staff often provides nutrition information to service members during meal selection. However, it is uncertain if staff members possess a higher nutrition knowledge (NK) than their patrons.

Objective: Evaluate and compare the NK of DFAC staff members and their patrons.

Study Design, Setting, Participants, Intervention: A 19-question true/false military NK survey was administered to 48 staff and 125 patrons at Fort Carson, CO. A confidence score was also included to stratify NK scores. Possible question outcomes were confident and correct (CC), confident but incorrect (CI), unconfident and correct, or unconfident and incorrect. Data analysis was restricted to CC and CI responses. Volunteers were predominately male (71\%), junior enlisted Soldiers (90\%) between the ages of 18 and 34 years.

Outcome Measures and Analysis: Descriptive data are reported as mean \pm standard deviation (SD) or frequency (n / \%). Independent t-test and chi-square analyses were conducted comparing patron and staff total NK score, \%CC, and \%CI scores.

Results: CC scores (mean \pm SD) were similar between culinary staff ( $40 \pm 16 \%)$ and patrons ( $41 \pm 21 \%)$, and CI scores were higher for staff $(31 \pm 16 \%)$ compared to patrons $(25 \pm 16 \% ; P=.024)$. More staff responded CC that at least half of the plate should be fruits and vegetables (90\% vs. $70 \% ; P=.021)$ but staff had lower CC scores on questions related to dietary fat $(50 \%$ vs. $77 \% ; P=.008)$ and protein as an energy source (13\% vs. $38 \% ; P=.005)$. Patrons who had $\geq 3$ hours of nutrition education had higher NK scores (53\% CC) compared to only 1-2 hours (39\% CC; $P=.044)$ and no education (39\% CC; $P=.015)$.

Conclusions and Implications: DFAC culinary staff are not more knowledgeable about nutrition than patrons and may unknowingly provide inaccurate information. Future initiatives should consider a minimum three hours of nutrition education for DFAC staff to promote dissemination of accurate dietary guidance.

Funding: U.S. Army Research Institute of Environmental Medicine.

\section{P10 Adolescent Self-Assessment of Cooking and Kitchen Skills}

Katera Moore, PhD, MES, Agatston Urban Nutrition Initiative; Melissa Sattler Gordon, RDN, MSPH, RD, msattler@sas.upenn.edu, Agatston Urban Nutrition Initiative, 3451 Walnut Street, Suite P117-A, Philadelphia, PA 19104

Background (Background, Rationale, Prior Research, and/or Theory): The Netter Center for Community Partnerships, Agatston Urban Nutrition Initiative (AUNI) provides summer high school programming and job development focusing on peer nutrition education. This study examines self-assessments of adolescents at the conclusion of the program compared to a control group of Philadelphia high school students who did not participate in the program.

Objective: To assess and compare adolescent confidence in cooking skills at the end of a six week nutrition education program.

Study Design, Setting, Participants, Intervention: The AUNI Philadelphia Youth Network (PYN) summer program engaged 36 primarily African-American adolescents for six weeks, 20 hours per week, in cooking, nutrition education, and peer education and community outreach activities. Evidence-based nutrition curriculums were used along with Career and College Readiness training. At the program conclusion, students were given a survey to selfassess their cooking skills and knowledge.

Outcome Measures and Analysis: The survey was constructed with a chef who determined cooking skills necessary for home and professional settings. Three questions were asked about skills regarding working with community members. Adolescents were asked to rate their skills on a scale of zero (no knowledge) to five (expert). The same survey, with the omission of one program specific question, was administered to students who did not participate in the program. Results were averaged for each question and each group.

Results: For eight of the nine questions, program students $(n=32)$ average rating of their skills were statistically significantly higher $(P<.01)$ than the averages of nonprogram students $(n=35)$. For all questions, program students averaged above four, demonstrating a high level of skill confidence.

Conclusions and Implications: Nutrition education programs that include a skill building and community outreach component could increase students' confidence in their own cooking abilities. Based on existing research, this could have an impact on improved nutrition related behaviors.

Funding: Supplemental Nutrition Assistance Program-Education.

\section{P11 Development of an Instrument Measuring Perceived Environmental Healthfulness: Behavior Environment Perception Survey (BEPS)}

Jade McNamara, MS, University of Rhode Island; Melissa D. Olfert, DrPH, LDN, RDN, West Virginia University; Morgan Sowers, MS, RD, LDN, University of Tennessee; Sarah Colby, PhD, RD; Adrienne White, PhD, RDN, FAND, University of Maine; Carol Byrd-Bredbenner, PhD, RD, FADA, Rutgers University; Kendra Kattelmann, PhD, LDN, RD, FAND, South Dakota State University; Lisa Franzen-Castle, PhD, $R D$, University of Nebraska-Lincoln; Onikia Brown, PhD, $R D$, Auburn University; Tandalayo Kidd, $P h D, R D$, University of Tennessee; Karla Shelnutt, PhD, RD, University of Florida; Geoffrey Greene, PhD, LDN, RD, ggreene@uri.edu, University of Rhode Island, 41 Lower College Road, Kingston, RI 02881

Continued on page S13 